\title{
Mining in consolidated and presupported karstified ground conditions
}

\author{
J.F. Talbot Vedanta Resources Lisheen Mine, Ireland \\ J. Burke Vedanta Resources Lisheen Mine, Ireland
}

\begin{abstract}
The Lisheen Mine is a mature underground operation approaching the final stages of extraction. A large percentage of the remaining ore is located in either poor or very poor ground class conditions. The development necessary to access these stopes and the eventual safe mining of them presents challenges to the rock mechanics understanding of the ground behaviour, the support management and the planning of the final stope extractions.
\end{abstract}

The experience in managing the ground conditions on the mine over the last 10 years has allowed a good understanding of the ground behaviour. A set of support techniques and methodologies have been developed along with the tools to manage the poor ground conditions.

The ore body is hosted within the Waulsortian limestone at a depth of between 70 and $230 \mathrm{~m}$. The rock is extensively faulted with deep karstic weathering causing degradation of the strong limestone into sand and clays and eroding sections of the massive sulphide orebody. The occurrence of major water inflow along the faulting creates hazards such as pressure build up in sand filled features and the reduction of cohesion from what is an intensely jointed roof.

Much of the early geotechnical work involved predicting the location of the poor ground zones and characterising their behaviour. This information was used to assist in the design layout of the stope panels and positioning of long-term access ways.

This approach was supplemented by an extensometer monitoring and ground behaviour observation programme. Selected area numerical modelling and back-analysis using suitably modified rock parameters were used in confirming the effectiveness of the support and mining designs.

The introduction of paste backfill allowed for long hole open stopes and more aggressive pillar mining. The introduction of cable bolting facilitated the design of larger spans and shotcreting provided stability to slender pillars and surface support to fractured and weathered ground.

Fibreglass cable bolting and the later acquisition of a mechanical cable bolter have allowed for the remote pre-support of large spans of poor ground in open stopes.

Together with critical stope assessments incorporating modified stability graph techniques, span management, blasting control and strategic paste fill placement, large stopes in extremely poor ground are being successfully mined.

To access these stopes a NATM method utilising shotcrete, bolting and cables were developed. However, in extremely poor ground this evolved to include shotcrete arches and spiling bars. In many cases the inability to consolidate 'support', or 'strengthen' would seem to be better words giving the specific meaning of consolidate in geotechnical engineering) the ground ahead of the development even with spiles resulted in the collapse of the drive immediately following the blast.

The predrilling and high pressure grouting of a grout curtain ahead of the face showed promise but was time consuming and unpredictable.

The introduction of drill-and-forget spiling bars followed by pressure grouting has allowed both the consolidation (comment as before) and reinforcement of ground ahead of the face. This has proved to be 
quicker and easier to implement and gives more control over the pressure grouting. This support technique combined with good blasting design has allowed the mine to access areas that previously were considered unmineable.

The use of long bulbed cables, fibre-reinforced shotcrete and high pressure grouting with drill and forget spiles have now become a ground control management tool at Lisheen allowing the safe and economic extraction of high grade ore stopes in extremely poor ground conditions.

\section{Introduction}

The Lisheen Mine is located in Co. Tipperary, Ireland and commenced production in 1999. It is a high grade orebody mining $1.4 \mathrm{mtpa}$ at $12 \%$ zinc and $2 \%$ lead.

Mining methods used are a combination of room and pillar, drift and fill and increasingly long hole open stoping (LHOS) at depths of between 70 and $230 \mathrm{~m}$ below surface.
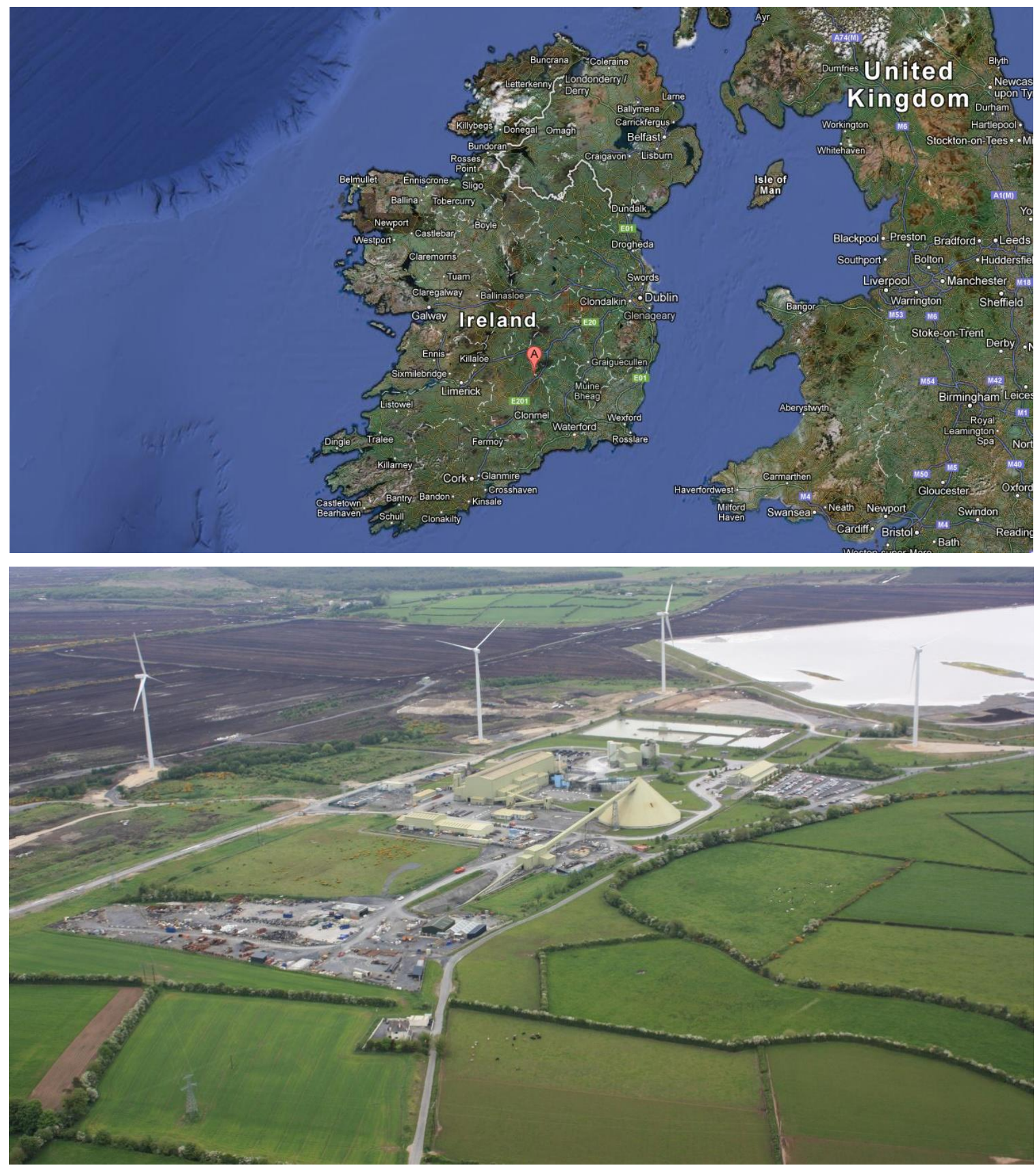

Figure 1 Lisheen Mine, Co. Tipperary, Ireland location and aerial photograph 


\section{$2 \quad$ Mining environment}

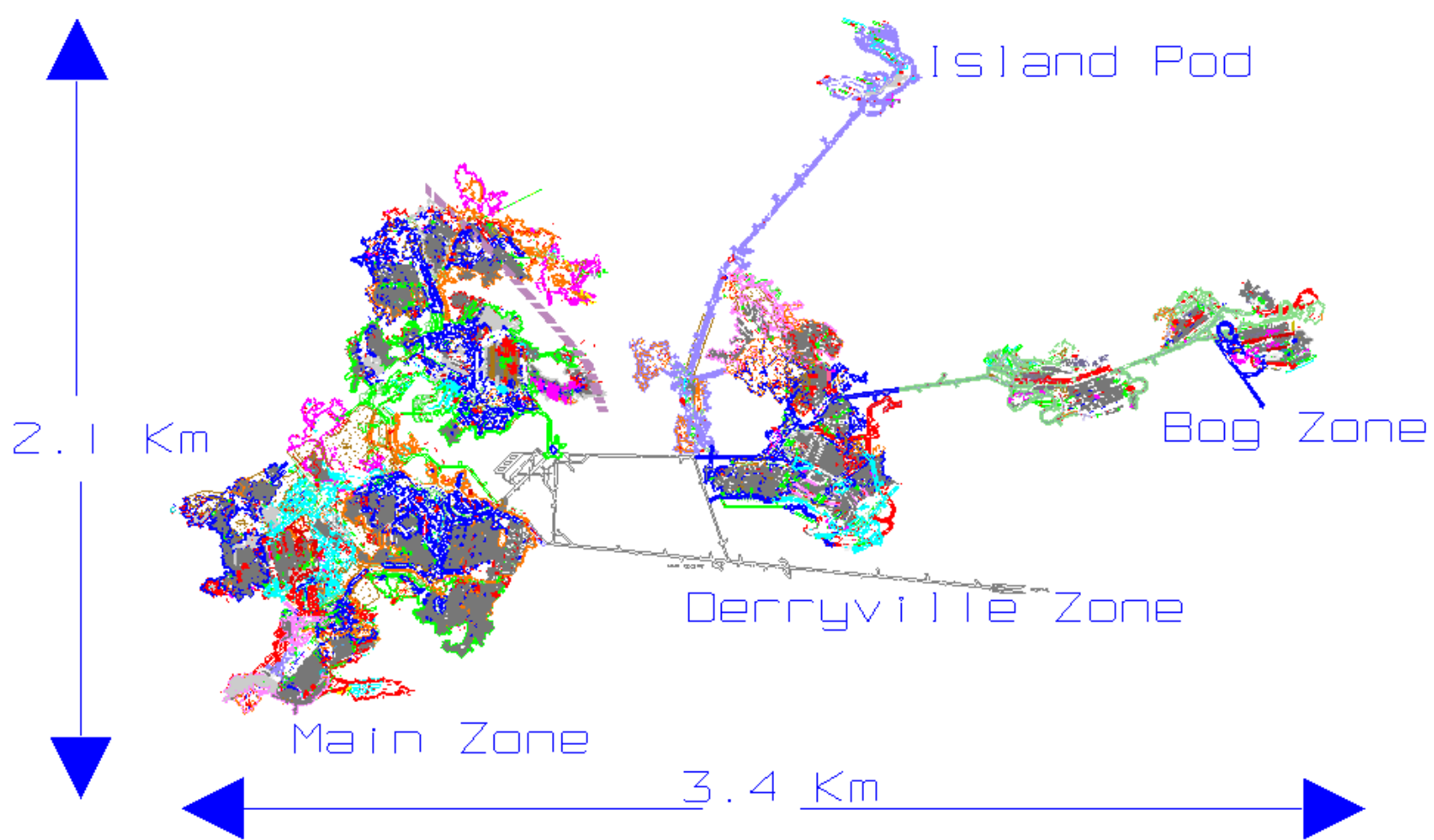

Figure 2 Lisheen Mine map of zones and scaled

The orebody lies at the base of a Waulsortian Reef Limestone unit which is heavily dolomitised. The orebody is bounded on the southern side by a northeast trending main mineralising fault and the orebody is criss-crossed by a series of en-echelon northwest trending structures. The orebody is underlain by a footwall of an Argillaceous Bioclastic Limestone (Güven et al., 2007).

The host rock is mostly massive and extremely strong in its intact state with strengths of up to 120-150 MPa based on laboratory testing. While it is strong it is rarely unaffected by structure which reduces its rock mass strength (estimated as) between 30 and $60 \mathrm{MPa}$ based on a refined strength using Roclab.

The sulphide rich mineralisation process has 'leached' large sections of the hangingwall and areas around structures, giving rise to sandy clay like material which is nearly impossible to support by conventional means. It is also difficult to determine the exact location of this weathering and the exact degree of weathering that has occurred in a particular area.

The ore horizon is usually massive sulphide rich material. It tends to have a lower intact strength than the hangingwall material and is subject to similar degrees of structural damage and weathering as the Waulsortian unit. The ore horizon is also subject to degradation by the oxidation of exposed iron sulphide rich ore which can cause geotechnical issues in longstanding and back areas.

The footwall unit is a thinly bedded argillaceous limestone unit which is relatively strong in compression but weak in shear due to the presence of shale bands in between the thin narrow spaced beds. When lying flat, this unit presents little or no problem geotechnically and exposure allows slabbing to occur causing swelling of the clay bands resulting in loss of cohesion. Large blocks or wedges can slide along the weak shaley bedding planes if not secured with non-standard support such as cable bolts.

Lisheen is a low in situ stress environment with the principle stress orientated perpendicular to the main mineralising structure in a northwesterly direction with a magnitude of $10.8 \mathrm{MPa}$. The secondary and tertiary stress magnitudes are estimated as being $5.4 \mathrm{MPa}$. With Lisheen in the tertiary stages of mining 
there are high mining induced stresses in some areas. Principle stresses of up to $50 \mathrm{MPa}$ have accumulated on remaining pillars due to open spans in excess of $200 \mathrm{~m}$ created in the primary and secondary phase of mining.

Structurally, aside from the main mineralising structure which trends southwest-northeast, there are a series of North West-South East trending structures thought to be secondary conduits for mineralising fluids. These ' $F$ ' structures have a large degree of weathering surrounding them. Where necessary barrier pillars have been left to provide confinement. In many cases these pillars are sited in ground that would be extremely difficult to mine (Güven et al., 2007).

Along with poor ground the major structures in Lisheen also carry large quantities of water (Figure 3). The mine is currently pumping greater than 80 million litres of water daily from underground, with 17 million litres of that total coming from one source. This can make supporting some of the major features and ground at Lisheen even more difficult, e.g. the adhesion of shotcrete or the ability to grout in cables.

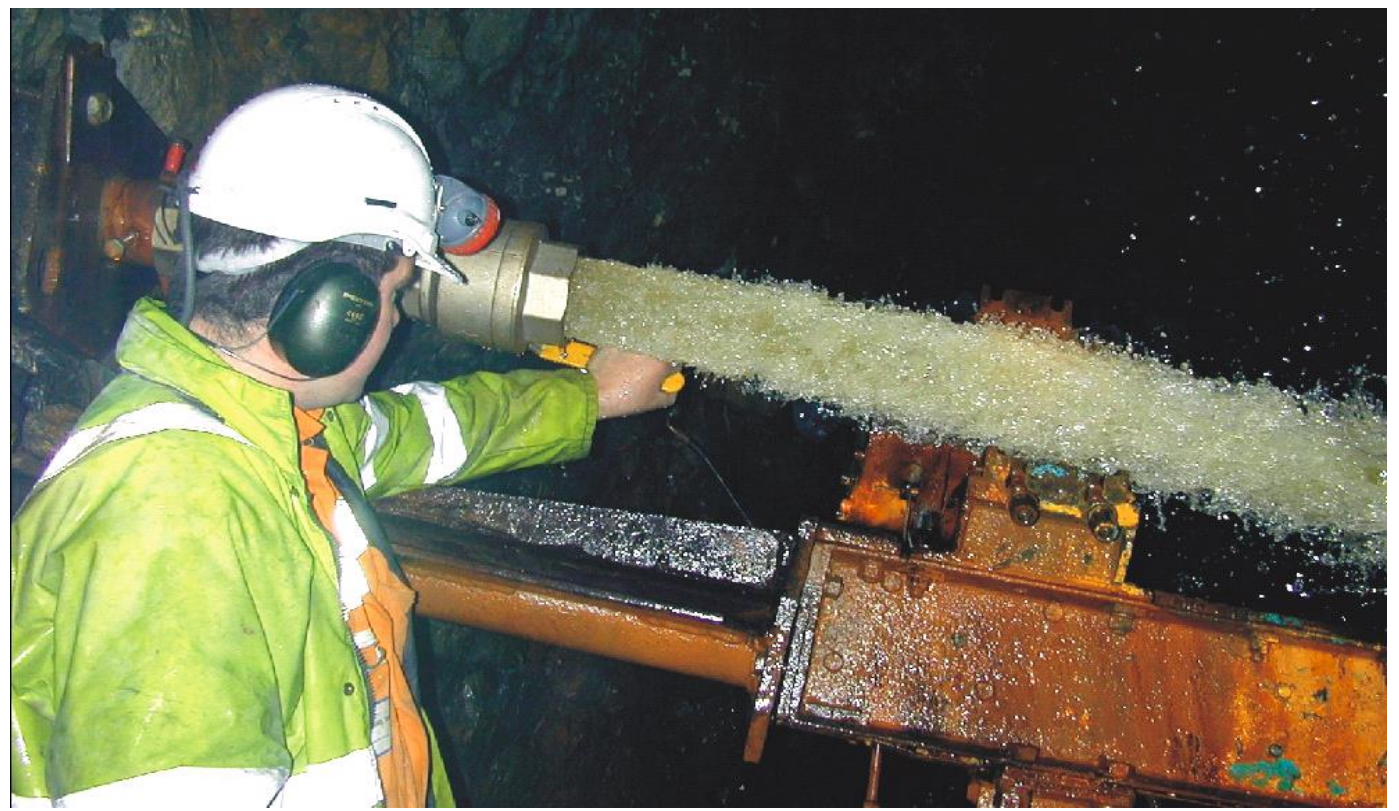

\section{Figure 3 An example of the water flow from a single source at Lisheen}

\section{$3 \quad$ Mining methods}

The mining method selected in any area will depend on the orebody thickness, grade, orientation and ground conditions.

\subsection{Long hole open stoping (LHOS)}

Long hole open stoping is commenced by driving a primary drive along the footwall, supporting as required with rebar, shotcrete and cables. Once the development is complete in areas where poor ground has been identified, pre-support in the form of long bulbed cables are drilled through the orebody and at least $5 \mathrm{~m}$ into the hangingwall or solid ground. The entire cable length is encapsulated in grout.

Once completed the production drilling starts and the stope is retreated on a ring by ring basis utilising remote mucking. Some of the stopes at Lisheen can be up to $30 \mathrm{~m}$ high, $25 \mathrm{~m}$ wide and $100 \mathrm{~m}$ long with individual blasts of between 2,000 and 10,000 tons. Without pre-support weathered zones above the hangingwall would cause significant overbreak, dilution, air blast and possibly caving. 


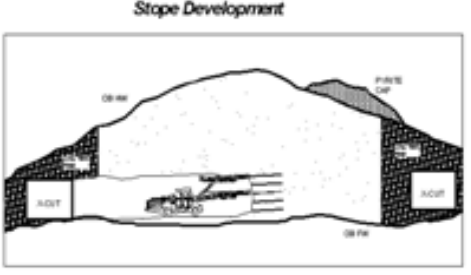

Phase 1 - Development

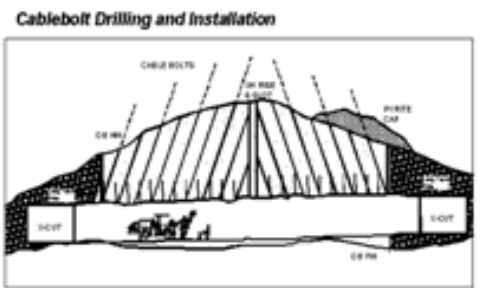

Phase 3 - Cable Bolting
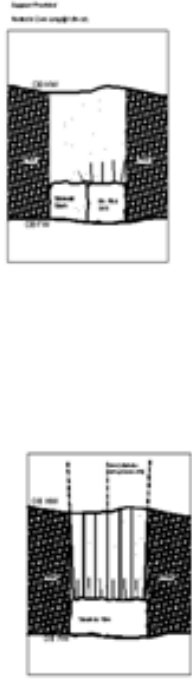
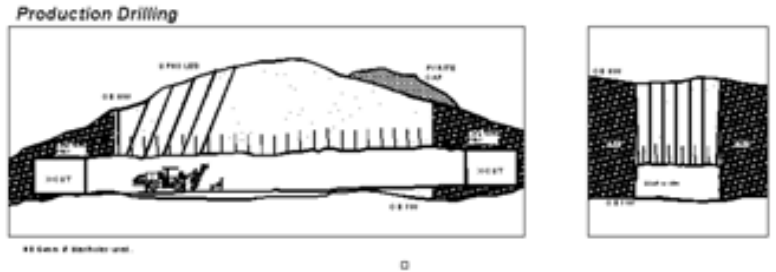

Phase 2 - Production Drilling

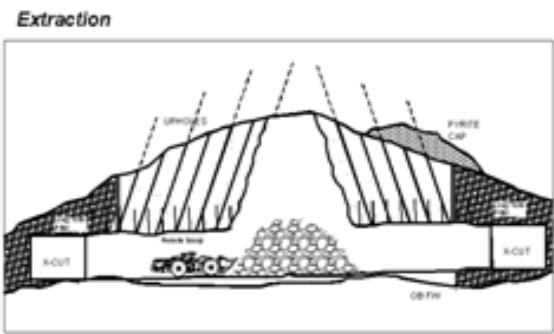

Phase 4 - Extraction

\section{Figure 4 Long hole open stoping at Lisheen}

\subsection{Drift and fill}

Drift and fill mining is utilised in areas where the ore is not thick enough to justify stoping and not thin enough to room and pillar. Lisheen uses a modified method slashing the $6 \mathrm{~m}$ wide primary development drive out to $10 \mathrm{~m}$ on retreat. The drift is then paste filling while developing the parallel drift leaving a $10 \mathrm{~m}$ pillar in between. The use of long holes and remote mucking to retreat the sidewall slash ensures a quicker and safer turnaround of the stope. Careful sequencing of the extraction ensures that the secondary drifts are removed from the centre to the abutment of the panels. This has successfully allowed the total extraction of panels of greater than $150 \mathrm{~m}$ in extent.

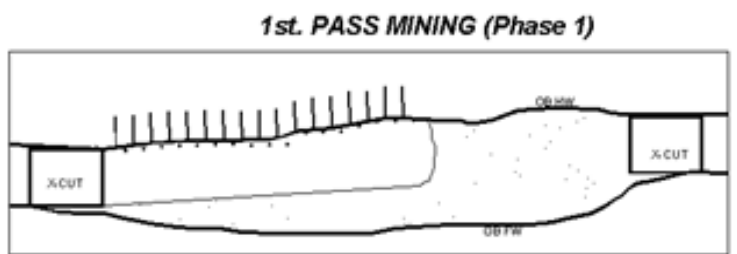

Phase 1 - Drift and Fill First Pass Mining - $5 \mathrm{~m}(\mathrm{w}) \times 4.5 \mathrm{~m}(\mathrm{~h})$

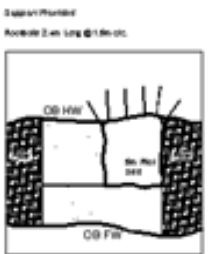

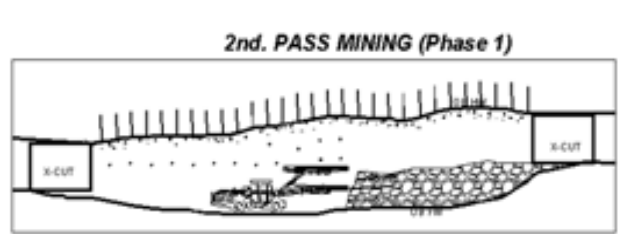

Phase 4- Second Pass Mining - Drift and Fill

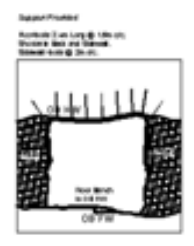

Phase 3 - Install sidewall bolts and shotcrete on backs and sidewall

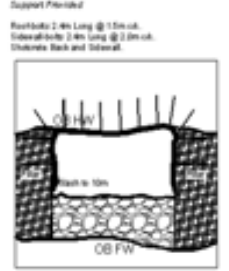

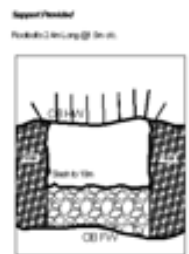

Phase 2 - Slash to $10 \mathrm{~m}$

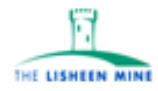

Figure 5 Drift and fill mining at Lisheen 


\subsection{Room and pillar}

Where the ore is thin, it has multiple lenses or poor ground conditions, a room and pillar technique aiming for one hundred per cent extraction is used. Occasionally yield pillars are used on retreat for local ground stability where deemed necessary by poor conditions. The pillars are closely monitored for changes in condition throughout the extraction sequence and can be sacrificed or the extraction sequence accelerated should the need arise.

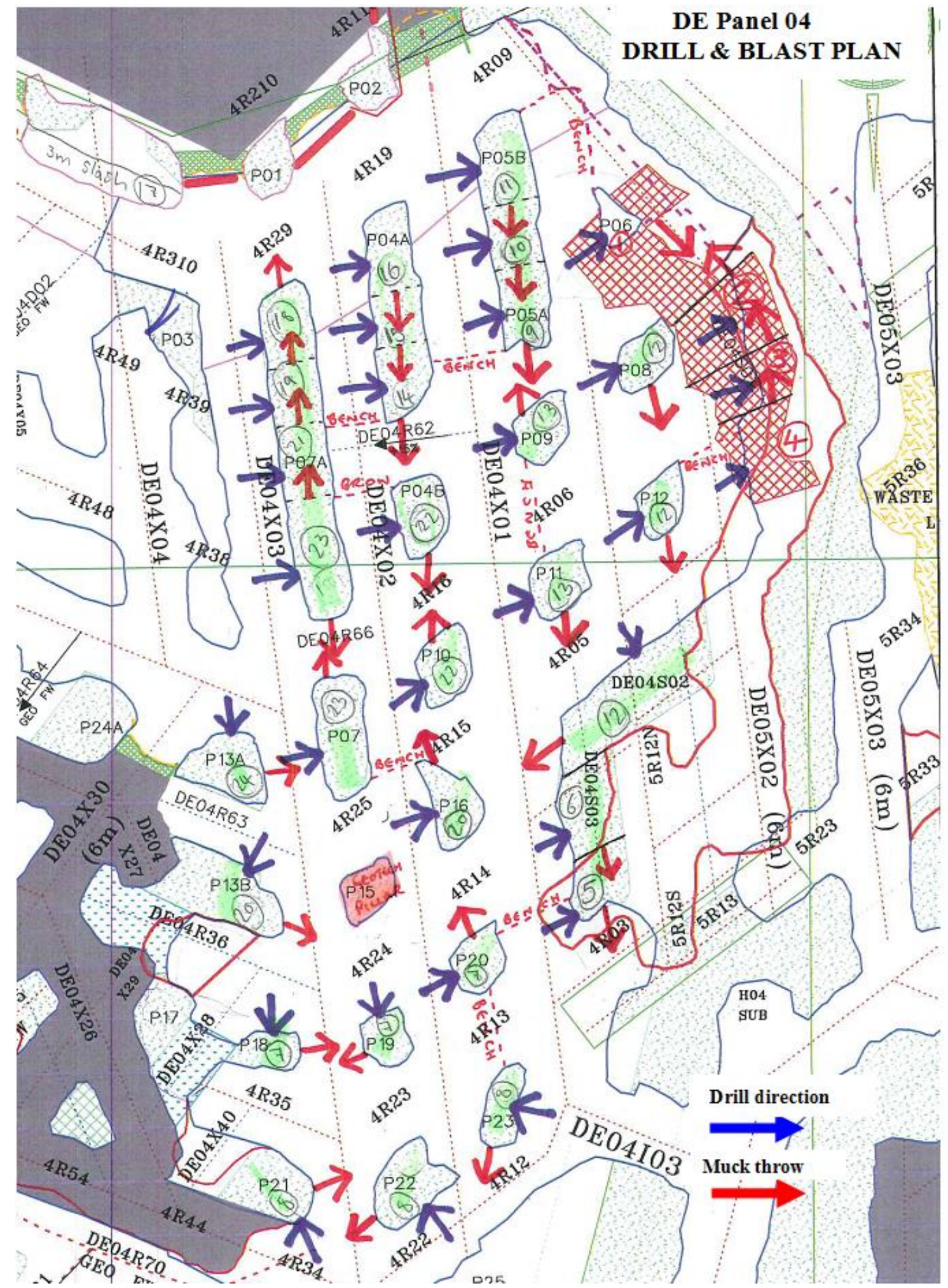

Figure 6 Rooms and pillar mining sequence 


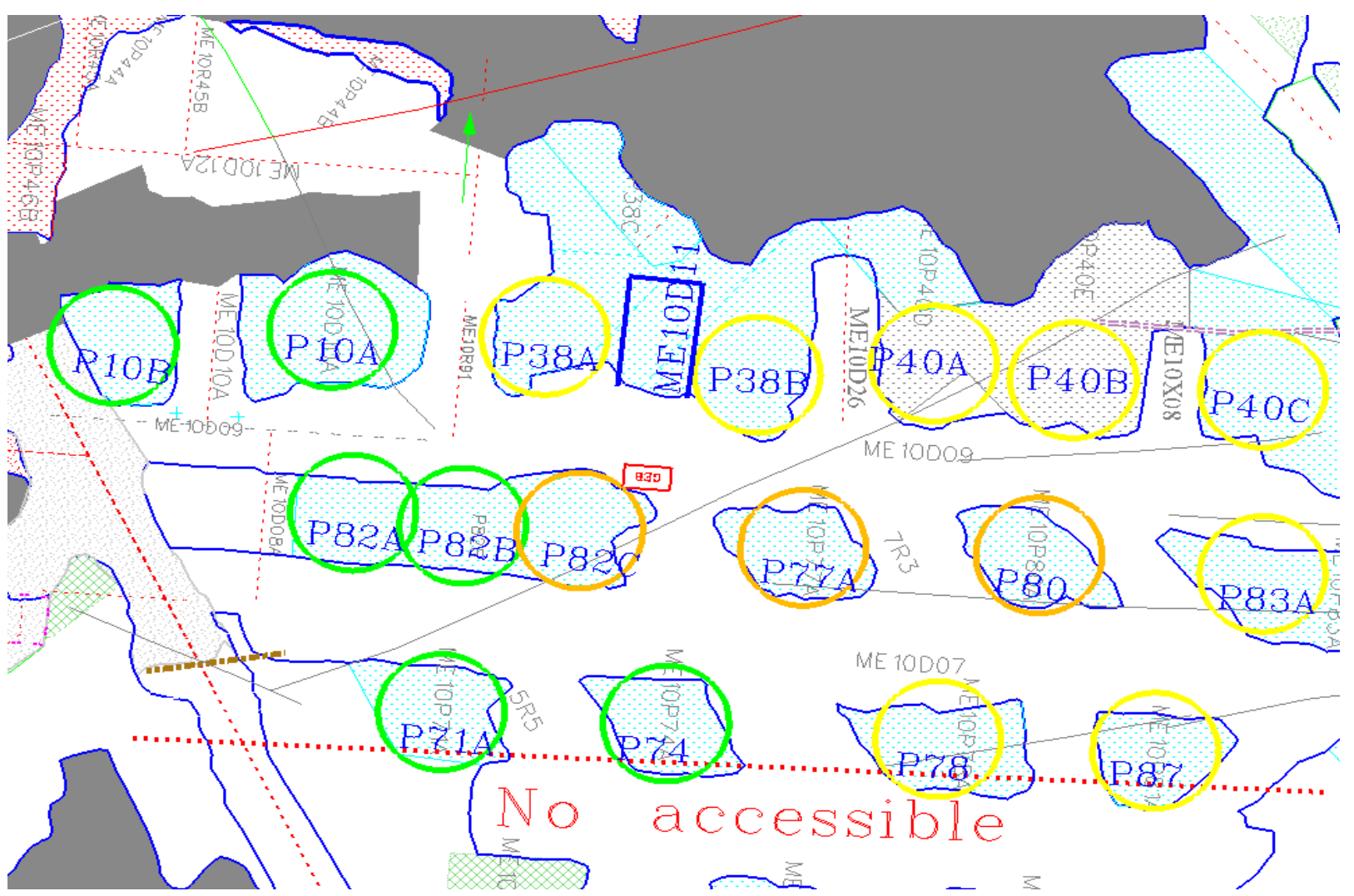

Figure 7 Room and pillar mining - pillar classification

Primary development is carried out using a conservative pillar strength design with a factor of safety of two. This produces a squat pillar usually $8 \times 10 \mathrm{~m}$ and is verified by numerical modelling and close observation of the development. Panels are designed around the orientations of major structures and ground conditions. A suitable hydraulic radius would be designed for the panel that could vary from three in very poor ground to a maximum of 25 in very good ground. A strict protocol to ensure the maximum safe extraction of the panel is used that includes pre-drilling pillars, remote mucking, monitoring of both the roof beam and pillar behaviour and strict adherence to the individual pillar removal sequence.

The variety of mining techniques as well as the variability of ground conditions at Lisheen provide for an orebody which is a high drain on resources and a requirement for a highly trained and skilled geotechnical department.

\section{$4 \quad$ Ground conditions}

The ground conditions at Lisheen vary considerably depending on location, mineralogy of the orebody, presence of major geological structure and position of excavations within the stratigraphy. In its intact state the host rock unit is extremely strong. The rock unit is a reef limestone which was heavily dolomitised during the first stage of mineralisation. There is little or no bedding within the unit owing to the slow nature of sediment deposition during the formation of the rock.

Where the host rock has been partially dolomitised it creates a unit known as a Black Matrix Breccia (BMB). This unit features clasts of heavily dolomitised rock surrounded by a matrix of undolomitsed Waulsortian limestone. The BMB is a chemical breccia as opposed to a tectonic breccia and, therefore, it is still an extremely strong unit in its intact state.

The strength of this rock in its intact state is generally in the range of 120-150 MPa but has been found to exceed $200 \mathrm{MPa}$ in individual samples. Most of the mine's drilling and blasting techniques are designed to maximise advance and fragmentation of the stronger ground at Lisheen and are often not applicable mine wide. 
The footwall unit is an argillaceous bioclastic limestone which, in its intact state, also has a high compressive strength of between 60 and $100 \mathrm{MPa}$. However, due to the presence of argillaceous bedding within the unit, it is very weak in shear. Because of this, when not orientated horizontally, it can pose a significant risk of block failure in an excavation.

The condition of the ore unit varies significantly based on the degree of mineralisation, mineralogy, iron sulphide content, weathering and structure. The mineralisation can be low to medium grade disseminated mineralisation contained in the BMB matrix. This type of mineralisation usually poses little or no geotechnical problem in its intact state, although sometimes it is overlain by a massive pyrite cap which, when exposed in the roof of an excavation, can degrade over time causing a potential beam failure.

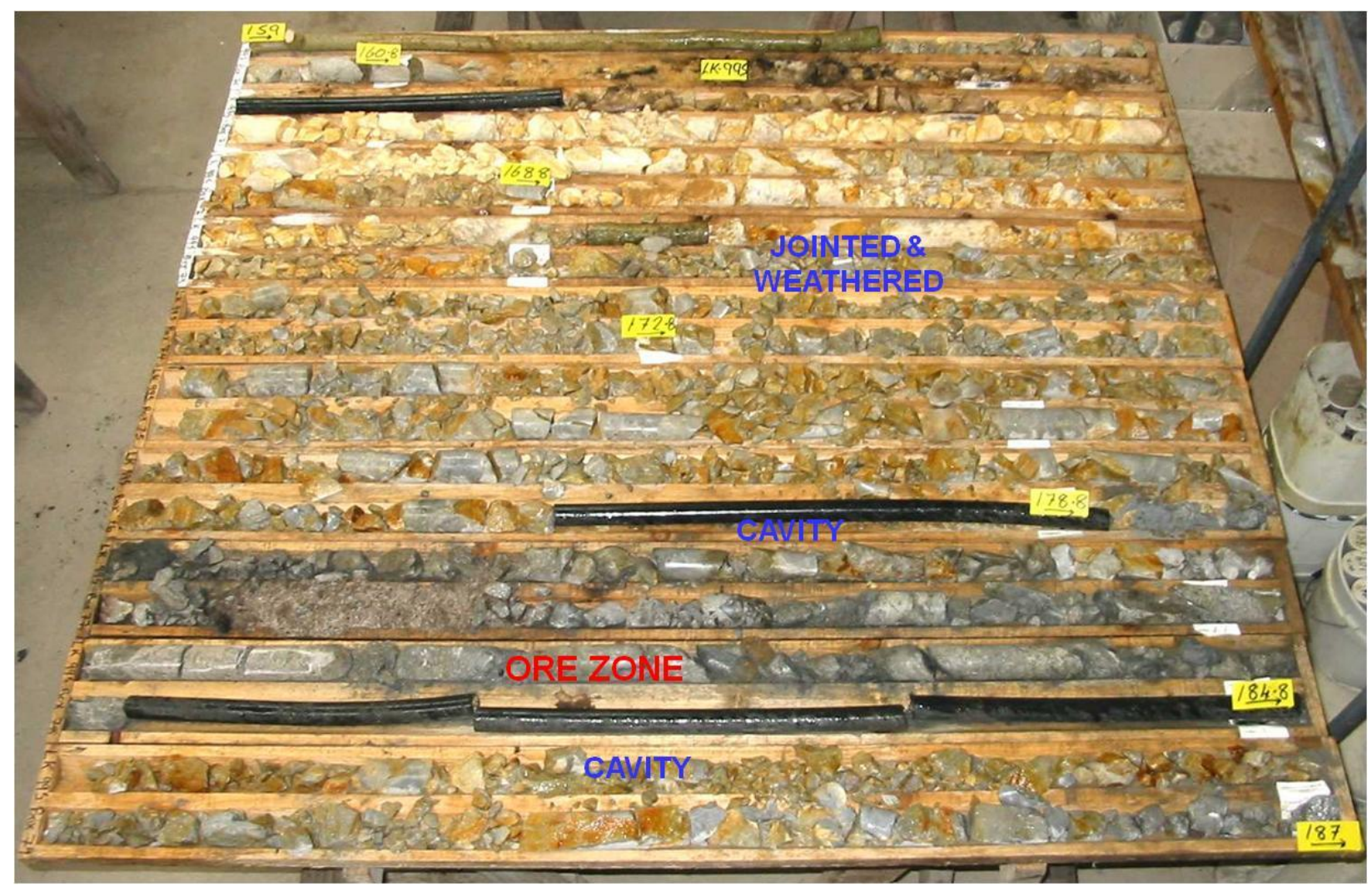

Figure 8 An example of a diamond drill hole from surface with poor ground conditions

The degree of mineralisation can increase right up to massive sulphide mineralisation where virtually the entire host rock unit has been replaced with sulphide rich ore material. Massive sulphide is generally strong in its intact state although, depending on its iron content, it can degrade over time causing corrosion of steel support and swelling or cracking of shotcrete.

The majority of poor ground found at Lisheen is as a result of weathering either through 'leaching' of the zone directly above the hangingwall, or through weathering associated with the large structures cutting through the orebody. The degree of weathering can vary from a light yellow/orange staining of the rock coupled with a reduction in intact rock strength and an increase in minor fractures within the rock up to complete and total destruction of the intact rock down to the level of oxidised silt, sand and clay with little or no compressive strength (Figure 9). This latter type of ground is immune to almost all types of anchored support and can only be managed through sprayed concrete and high pressure grouting and spiling (Figure 8). 


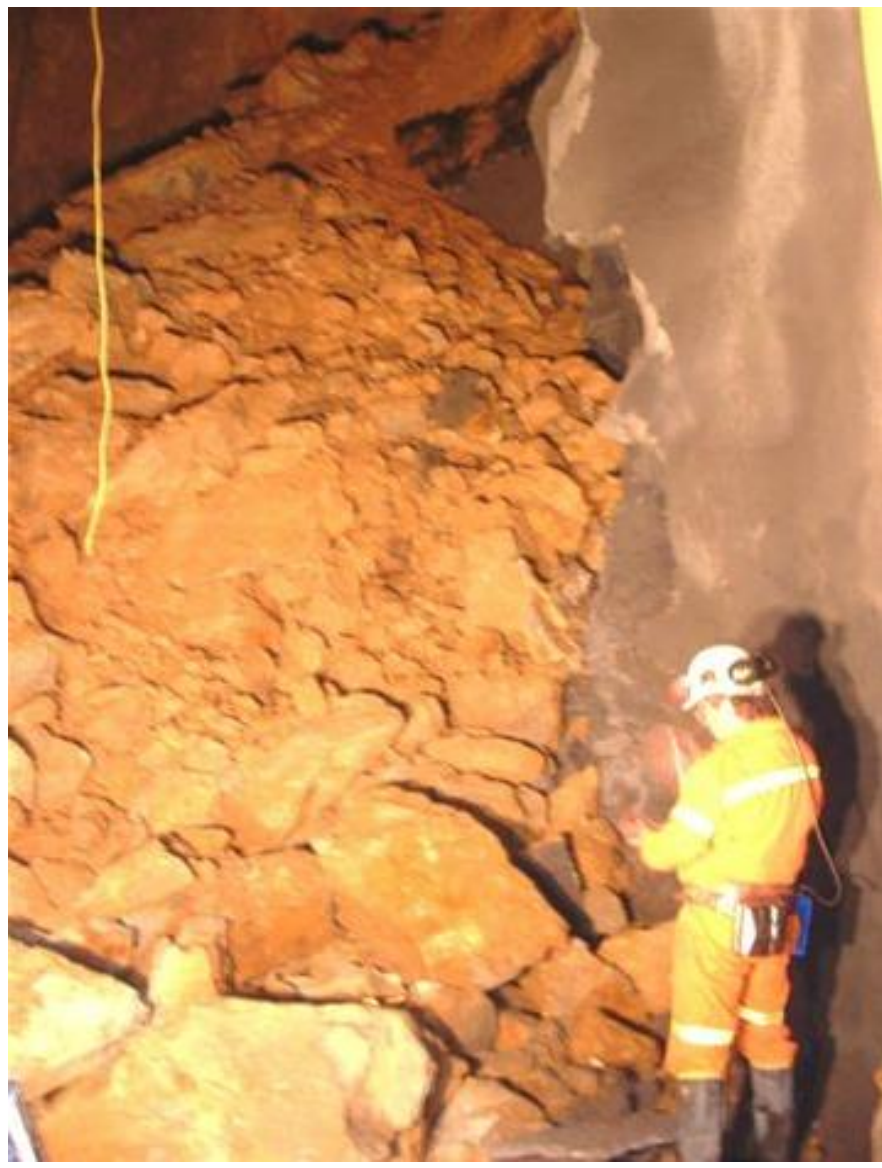

\section{Figure 9 Uncontrolled fall of ground at Lisheen showing weathered ground}

\section{$5 \quad$ Established support techniques}

Lisheen adopted a standard of mechanised rebar bolting 'to the face' very early in the mine life. The wet nature of the hangingwall rock made the adoption of a resin bonded rebar necessary. The need to install $+20,000$ rebars a year necessitated the use of an automated bolting system. Three Atlas Copco Boltecs provide the standard support for the mining sections. They drill and install a $2.4 \mathrm{~m}$ long Y 25 rebar in a $33 \mathrm{~mm}$ hole, tensioned using two speed resins to five tonne. The bolts are installed on a $1.5 \times 1.5 \mathrm{~m}$ diagonal pattern with sidewall bolting if necessary, particularly in excavations $6.5 \mathrm{~m}$ high and over and where paste fill is exposed (Burke, 2008).

The dedicated non standard support crew is provided with a Spraymec 1050 WPC shotcrete machine to spray $+12,000 \mathrm{~m}^{3}$ of shotcrete per year. The requirement to construct an engineered backfill barricade utilises approximately $30 \%$ of this shotcrete, the remainder going to support.

A minimum thickness of $50 \mathrm{~mm}$ is used to seal poor ground with an unreinforced shotcrete. In very poor ground a $75 \mathrm{~mm}$ thickness of shotcrete reinforced with $5 \mathrm{~kg} / \mathrm{m}^{3}$ of synthetic fibre is used to achieve a strength of $50 \mathrm{MPa}$ at 28 days with an energy absorption of 1,200 joules at $40 \mathrm{~mm}$ deflection (Melbye, 2006).

Two Atlas Copco LC2 jumbos were modified with a basket and shorter slide to serve as a multipurpose support platform installing cable bolts, mesh, spiles, split sets, drill probes and instrumentation.

The standard cable bolt used is a $15.2 \mathrm{~mm}$ Birdcage with a nominal cage size of $38 \mathrm{~mm}$ and a bearing capacity of $250 \mathrm{kN}$. The bolt length can vary but the standard is $6 \mathrm{~m}$ long. Most cables are plated and tensioned. This type of cable is very suited to the soft ground conditions allowing a weaker water cement ratio to be used to obtain a better bond strength and fill all cavities and cable cages (Hutchinson and Diederichs, 1996). 
In addition to the boom and basket rigs Lisheen also has a Sandvik DS 420 automatic cable bolter. The rig is used to deal with the increasing requirement for pre-support of the hangingwall of poor ground stopes. In addition it is utilised to remove the workmen from installation risk in extremely poor ground headings. The rig uses $15.2 \mathrm{~mm}$ diameter bulbed cable and is capable of installation lengths of up to $25 \mathrm{~m}$. Approximately $30 \mathrm{~km}$ of cable is installed per year of which half is presupport of stopes and the remainder face support.

Although the established support techniques allowed us to safely mine in most ground conditions, the shortcoming of these systems was that they could not function in exceedingly poor ground conditions. In the unconsolidated ground conditions cable bolt holes were collapsing before the rigs were able to run the cable up the hole or grout it, and development rounds were overbreaking in poor ground to a point where they became impractically high. When this happened development drives would either stop completely or cause excessive delays. A method of consolidating the ground prior to advancing the face was required in order to counteract these problems.

\section{Management of extremely poor ground}

\subsection{Geotechnical assessments}

One of the key challenges is to predict the extent of the poor ground, the degree of weathering and the measures or support techniques that are to be employed in an area.

Despite being in the tertiary stages of mining and having carried out extensive mining in the near vicinity of planned mining areas, it is still difficult to predict the exact location of major structures and the extent of weathering and poor ground associated with them. The effects of mining induced stress and displacement on such ground have also to be evaluated.

In order to prepare for entry into a stope, panel, development drive or remnant pillar area the geotechnical department staff have developed a list of data which must be gathered and evaluated prior to commencing mining. These area assessments form the basis of a risk assessment for all planned mining areas. The assessments are compiled under the following headings.

\subsubsection{Desk study}

The desk study is conducted by compiling as much of the information about the area as possible namely:

1. Predicted ground conditions: A database is constructed using geotechnical logs of boreholes for the first $2 \mathrm{~m}$ above the hangingwall and a category assigned to the ground conditions based on the logs. The ground classifications are site specific and rated on the critical parameters that influence the ground conditions at Lisheen namely RQD, fracture frequency and degree of alteration (Burke, 2008). The system is essentially the Barton Q prime system with a constant joint roughness coefficient. These are divided into 4 categories:

a. Class 1 ground conditions have a rating of between 61 and 100 and usually feature intact or near intact rock mass with little or no weathering. Class 1 ground is usually supported using standard bolting.

b. Class 2 ground conditions have a rating of between 41 and 60 . Class 2 ground is a slightly weathered slightly fractured rock mass. Class 2 ground is usually supported using a combination of standard rebar and occasionally shotcrete where necessary.

c. Class 3 ground conditions have a rating of between 21 and 40 and usually feature a moderately weathered rock mass unit with significant structure. Class 3 ground is usually supported with a mixture of bolting, shotcrete, cable bolts and mesh.

d. Class 4 ground conditions have a rating of between 0 and 20 and is usually associated with the worst ground conditions. Class 4 ground is highly weathered and fractured and is 
supported with a mixture of bolting, shotcrete, standard $6 \mathrm{~m}$ cable bolts, long cable bolts, pressure grouting and spiling.

2. Diamond drilling surface and underground: the geotechnical and geological logs of the surface and underground diamond drilling are scrutinised to identify major structure, zones of weathering and significant changes in lithology.

3. Local structure: the mine plans are scrutinised to determine if any of the structures encountered before can be found in the area being assessed and the possible impact on both development and stopes.

4. Core photos: photographs are kept for most of the surface boreholes and can be viewed electronically to verify the presence of large cavities, structures and the degree of weathering.

5. Face sheets: the face sheets of surrounding development are examined for geological information as well as a qualitative description of the ground conditions.

6. Pyrite hazard: an assessment of the presence of massive pyrite in the roof of excavations.

7. Existing support: support that is in place currently, its condition and how it is performing.

8. Recent mining: any mining that has been conducted in the area prior to commencing and its influence on the roof beam and stress transfer. If deemed necessary a numerical model is run to assist in evaluating the stress and displacement changes.

9. Span to be created: the maximum span that will be created at any stage during mining and its effect on both regional and local pillar support.

10. Pillar height to width ratio: either the existing height to width ratio of the existing pillars or the height to width ratio to be created at any stage during mining to evaluate the changing stress loading.

11. Paste exposure: is there paste exposed in any of the excavations and what is the quality and condition of that paste?

12. Extraction sequence: what is the planned extraction sequence and how will this fit with the ground conditions in the area? The extraction sequence must also take into consideration the impact on surface subsidence and the need to avoid differential movement.

\subsubsection{Underground inspection}

A visual confirmation of the findings of the desk study is undertaken to evaluate:

1. Stability assessment: a visual examination of the stability of the area from underground.

2. Support assessment: an evaluation of the support requirements and the existing support and its suitability and performance.

3. Pillar assessment: a classification of the condition of the pillars in the mining area based on a visual assessment and rate of deformation and how it matches predicted behaviour.

4. Risk assessment: a general categorisation and ranking of what the primary risks currently are, as well as those which will arise as a result of mining.

5. Further geotechnical investigations: a list of any recommended further actions required to be conducted in order to gain a better understanding of the ground conditions.

\subsubsection{Actions required}

A list of recommendations for the area in question:

1. Additional support required: support plans and instructions. 
2. Instrumentation required: does the area require physical monitoring activities such as stressmeters or extensometers?

3. Communication required: who needs to know this information and how do we communicate this information to them?

4. Follow-up summary on completion of the mining area: what are the learnings that have arisen as a result of the mining of the area? What would we have done differently with the benefit of hindsight? Also includes closure instructions for the panel, i.e. waste/paste filling.

The assessments allow us to predict what the ground behaviour in a particular mining area might be like before we commence mining, thus allowing us to introduce mitigation measures through support, monitoring, change in design or simply communication, which will allow the maximum extraction in the safest possible conditions as a result of mining in poor ground.

\subsection{Ground consolidation (strengthening and reinforcement)}

A continual improvement program to examine support methodologies and techniques was used to develop confidence in our ability to recover high grade ore in some of the Class 4 ground which had previously been either partially or totally written off.

Radical methods of ground stabilisation were required, particularly to deal with the unconsolidated sandy, silty clay-like ground. Pressure grouting using a packer and lance system and a high pressure pump with colloidal mixer was used in areas where this unconsolidated ground was encountered. This operation proved logistically difficult and, at pressures of up to 20 bar, the lance often caused problems with ensuring the packers stayed in place. The placement of the grout was difficult to control and would regularly appear in features behind the active face.

Lisheen also uses grouted spiles in the form of discarded drill steel coupled together and grouted into predrilled holes ahead of the face in order to try and reinforce the roof of development drives prior to advancing the face. These were only partially successful as keeping the hole open for installation, and grouting was very problematic. It was decided to trial Dywidag's drill and forget post-groutable spiles as a means of combining spiling and pressure grouting in the one installation.

The spiles are drill and forget threaded steels with a sacrificial bit. They are supplied in $2 \mathrm{~m}$ lengths, half of which have 'valved' sections for pressure grout placement. The valves in these bars stay intact (closed) during the drilling process and allow water flush to travel down the bore of the steels. The spiles are drilled on a design to the required length (usually 9-15 $\mathrm{m}$ ) with valved bars placed strategically along the drill string where grout is required.

Primary grouting is conducted using a low pressure pump in order to fill the annulus of the hole with grout. A plug and breather tube is installed at the collar in order to ensure that the area around the collar is fully grouted. When the primary grouting is complete the bore of the drill string is washed out and the grout allowed to set for 8-24 hours.

The drilling of the spiles and acceptance of the primary grouting will decide if pressure grouting is necessary to further consolidate the ground. Based on this information a mix design is made specifying the grout and pressures for each hole. This can vary from high Blaine micro cement with plasticiser to Ordinary Portland Cement depending on the void ratio and porosity of the ground.

A high pressure colloidal mixing pump is attached to the collar of the threaded bar which is now fully grouted in place and unable to move. The high pressure delivered by the pump breaks open the 'valves' and the thin recently set grout around the valves and allows grout to be placed at high pressure at various points down along the drill string all the way to the bit at the head of the string. This technique allows control of the placement of grout ahead of development ends as well as re-enforcing the roof with grouted spiles. 
The system has been in operation for 18 months and is now well established with a dedicated crew who can turn around a heading in three shifts with the placement of up to 5 tonnes of grout in a set of eight holes drilled $12 \mathrm{~m}$ ahead of the face.

\subsubsection{Monitoring}

With the mine now in its tertiary stage of mining, unsupported large spans in excess of $300 \mathrm{~m}$ are regularly being created. Regional monitoring to understand the beam behaviour and stress transfer has become even more crucial.

Dual height tell-tales with visual movement indicators are used to monitor near excavation movement. Vibrating wire stressmeters are used to monitor stress redistribution in regional pillars. Multi point borehole extensometers are used to monitor deeper hangingwall movement and beam failure. The data from the underground monitoring systems are compared with visual assessments of changes in ground conditions, such as the pillar monitoring system, in order to confirm the observations of the geotechnical department. The data can also be used to calibrate stress and displacement modelling and predict future movements or stress re-distribution in mining areas.

In addition to the underground monitoring an extensive network of precision levelling stations is installed on surface and these stations are read on a regular basis. There are also a number of contractometers installed from surface as well as a network of time domain reflectometers.

To facilitate the removal of high grade haulage pillars, some critical haulages (Figure 10) were re-developed through extensively mined out areas by mining through backfill. The tertiary mining sequence will place these critical haulages in areas of potential long term instability during the final stages of the mining process. These haulageways require an accurate, real time method of monitoring movement, due to the amount of traffic passing through them.

A method of remote sensing is being used to monitor these haulages. This uses a Leica TS30 total station and an array of reflector prisms installed at various interval along the roof and sidewalls to produce real time displacements that are checked daily of following nearby large blasts (Figure 11).

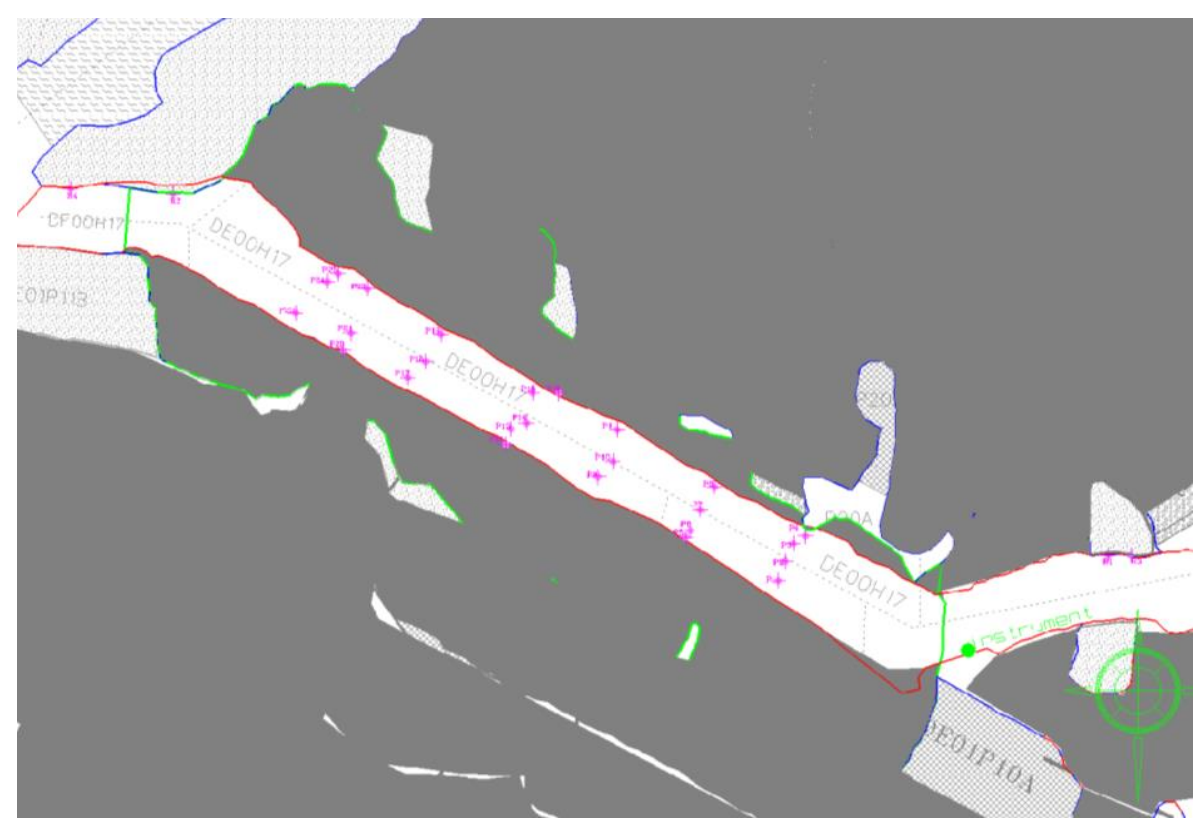

\section{Figure 10 Plan showing monitoring array and prism locations for a key haulage mined through paste filled stopes}

The system has been found to have a sub-millimetre accuracy and has been used to monitor sidewall swelling and minor amounts of roof movement following removal of pillars in the vicinity of the haulage. 
It is planned to extend the use of this system in more key haulageways and to use the data to make more accurate predictions of ground behaviour going forward.
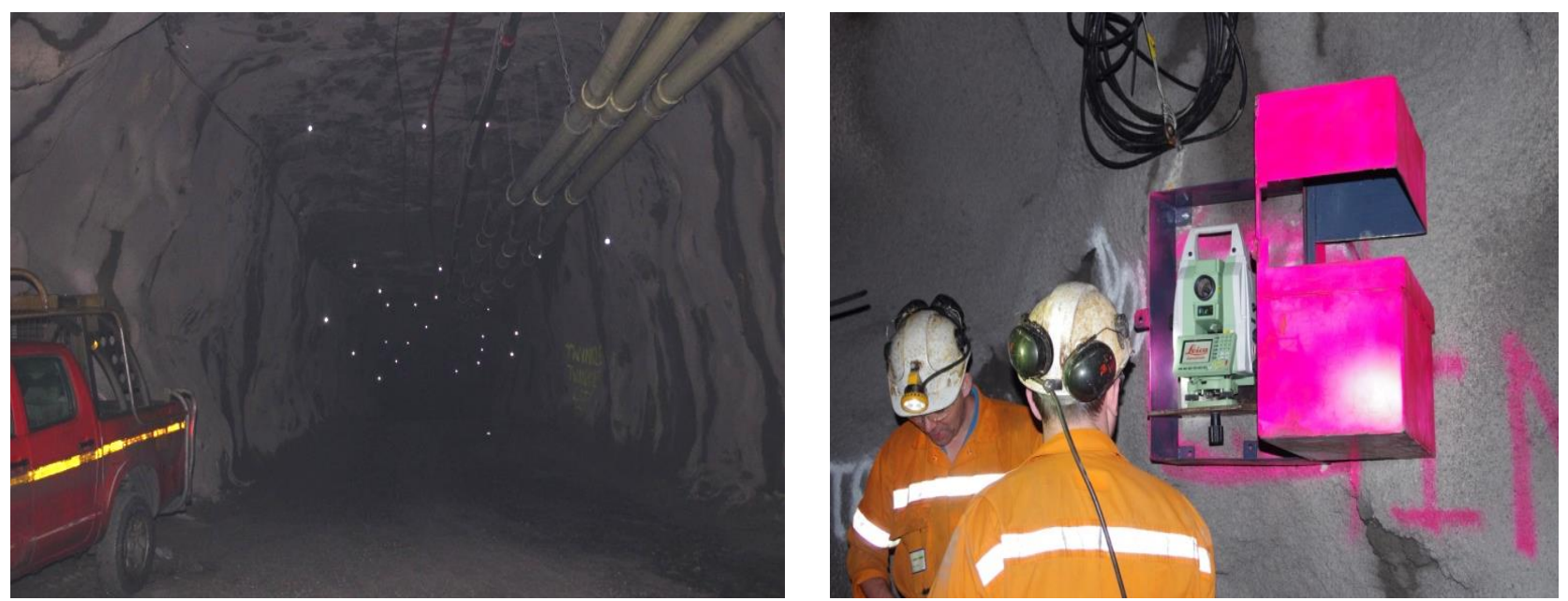

\section{Figure 11 Images showing the prism array and instrument}

\section{$7 \quad$ Conclusions}

A combination of advanced support techniques and accurate and holistic geotechnical data analysis at the Lisheen Mine has significantly assisted in the management of the safe extraction of mining areas in extremely poor ground conditions and in some circumstances has extended the mineable reserve.

Although many of the techniques used in managing the poor ground are site specific, they are applicable to many different ground conditions and have the potential for realising benefit for any mining operation. The technique applied at Lisheen is about getting the best out of the support resources available while exploring new inexpensive means of broadening the support tools available. At the same time geotechnical engineers are using all the information available to accurately predict variations in ground conditions in an individual panel and the likely geotechnical risks that are going to be encountered.

The technique applied is a fresh approach contrary to the usual mining response of throwing more and more resources at the problem. The changes made to the support processes at Lisheen will allow the operation to achieve maximum extraction safely, as the mine comes into its final stages.

\section{Acknowledgement}

The author thanks the staff and management at Lisheen for allowing publication of this paper, particularly the author's colleagues in the geotechnical department.

\section{References}

Burke, J. (2008) Ground Support in Karstified Ground Conditions, in Proceedings Sixth International Symposium on Ground Support in Mining and Civil Engineering Construction, T.R. Stacey and D.F. Malan (eds), 30 March-3 April 2008, Cape Town, South Africa, International Society for Rock Mechanics, Lisbon.

Güven, J., Passmore, M. and Harney, D. (2007) Updates on the Geology and Metallogenesis of The Lisheen Zn-Pb Deposit in Ireland, in Proceedings 9th Biennial SGA Meeting: Mineral Exploration and Research: Digging Deeper, 2007, Dublin, Ireland, Society for Geology Applied to Mineral Deposits, Klárov.

Hutchinson, D.J. and Diederichs, M.S. (1996) Cablebolting in Underground Mines, BiTech Publishers, Richmond.

Melbye, T. (2006) Sprayed Concrete for Rock Support, UGC International User Manual, Switzerland. 